\title{
Multiculturalism, biosemiotics, and cross-cultural friendship: An essay review of Olteanu's multimodal semiotics of culture
}

\section{Claus Emmeche ${ }^{1}$}

Review of Multiculturalism as Multimodal Communication: A Semiotic Perspective [Series Numanities - Arts and Humanities in Progress 9; Dario Martinelli, series ed.] by Alin Olteanu. Cham: Springer, 2019, xviii+140 pp.

More than merely a sum of cultures, plurality is a prerequisite for cultural genesis. Mainstream multiculturalist theory appears to ignore that cultures are intrinsically pluralistic. (Olteanu 1990: 7)

"Democracy also means voluntary choice, based on an intelligence that is the outcome of free association and communication with others. It means a way of living together in which mutual and free consultation rule instead of force, and in which cooperation instead of brutal competition is the law of life; a social order in which all the forces that make for friendship, beauty, and knowledge are cherished in order that each individual may become what he, and he alone, is capable of becoming."

(Dewey 1937: 474, quoted in Olteanu 1990: 71)

We are living in a world with intensifying global commerce and exchange between people coming from different ethnicities, cultures, and nations; speaking different languages. Not only do we meet people from other countries and cultures at work or in the marketplace, we increasingly form lasting social relations of love and friendship across ... 'cultures'? I wonder what makes something deserve the label 'intercultural'. Some of the persons dearest to me have a native background in Southeast Asia and Africa, and my closest friends and colleagues come from a variety of countries. A friend of mine considers himself to be a nomad with a hybrid identity. We move between countries and living different places for some

1 Section for History and Philosophy of Science, Dept. of Science Education, University of Copenhagen, Øster Voldgade 3, 1350 Copenhagen K, Denmark; e-mail: cemmeche@ind.ku.dk. 
years makes an influence and changes us, but are we representing multiple cultures? Maybe not exactly, if we are really all 'moderns', or, if you like, none of us has ever been completely modern (pace Latour). So, what is this fuss about multiculturalism? Can semiotics help us understand it? Having worked with biosemiotics for some years, I was thrilled when offered to review a book dealing with multiculturalism from a semiotic perspective, promising in its preface to have developed a "semiotic theory of multiculturalism". Now, having read it, I am reminded of the old blues song "The thrill is gone". I will try to explain why this is so. Was the reason a loss of focus, a lack of interplay between theory and case analyses, or something else? I will also illustrate some challenges of understanding the topics of the book through an example, the question of how to interpret friendship across cultures as seen from the point of view of cross-cultural friendship research.

Is there a standard notion of multiculturalism? The English edition of Wikipedia, in itself a multicultural and multilingual phenomenon, contains a very long entry on 'multiculturalism' and a brief one on 'polyculturalism'. The latter, rarer term is defined as "an ideological approach to the consequences of intercultural engagements within a geographical area which emphasises similarities between, and the enduring interconnectedness of, groups which self-identify as distinct, thus blurring the boundaries which may be perceived by members of those groups" 2 . In some sense, this is the approach adopted in the book about multiculturalism under review, though its author, semiotician Alin Olteanu does not use the term 'polyculturalism'. Olteanu follows polyculturalism in emphasizing the blurred boundaries between cultures.

The version of multiculturalism that is at the centre of Olteanu's investigation is not exactly the one explained at the beginning of the long Wikipedia entry (that underscores multiple meanings of multiculturalism). This entry suggests it is "a synonym for 'ethnic pluralism', with the two terms often used interchangeably, for example, a cultural pluralism in which various ethnic groups collaborate and enter into a dialogue with one another without having to sacrifice their particular identities"3. So, according to Wikipedia, polyculturalism allows one to appreciate blurred boundaries between a variety of different cultures, while multiculturalism is concerned with preserving and respecting the identity of such cultures.

Olteanu critically interrogates the notion of identity implied by influential

2 'Polyculturalism' at https://en.wikipedia.org/wiki/Polyculturalism was accessed in November 2019.

3 'Multiculturalism' at https://en.wikipedia.org/wiki/Multiculturalism was accessed in November 2019. 
versions of multiculturalism, especially the idea of culture as having an essential significance for defining the identity of all its members. Even though multiculturalists may aim at providing space for different cultures to co-exist peacefully, there is a risk of tensions due to cultural differences. In other words, multicultural ideology risks, as Olteanu rightly points out, to overemphasize (or essentialize) differences and ignore similarities between people from different cultures.

\section{The problems of culturalism}

Right from the beginning, Olteanu locates his theoretical intervention in the wider context of recent populist anti-democratic movements in democratic societies all over the world: the main purpose of the book is that of "criticizing the mainstream academic theories of multiculturalism, as particularly relevant to democracy, globalization, digitalization and intercultural communication that [...] failed to deliver a program for democracy and conviviality" (Olteanu 2019: vii). He claims that it is a problem for the humanities to face these challenges directly, due to a "comfortable and slothful lingering in academic discourse of an ideological theory of culture, first signalled by Eriksen and Stjernfelt" (Olteanu 2019: vii). What is this ideological theory of culture? His reference is to a highly recommendable analysis by Eriksen and Stjernfelt in their book The Democratic Contradictions of Multiculturalism (2012). The problem with the humanities, according to Olteanu, is that they have fostered a false and too holistic-totalizing notion of culture and cultural identity, a notion that can directly be taken over by nationalistic and chauvinistic politics (a discomforting case of an "impact" of the humanities). As Olteanu notes, "populist rhetoric often starts from the other end: It emphasizes a supposed importance of identity, cultural or otherwise, for the purpose of generating conflict and separatism. To have an identity means to be different from others. To have a cultural identity means to be the same as some, by opposition to others" (Olteanu 2019: ix).

In the book's six chapters Olteanu claims to develop a so-called semiotic theory of multiculturalism as an alternative to this ideological notion of culture. He does not distinguish between (1) actually creating such a theory (eventually inspired by or generalized from empirical investigations or other analyses of particular multicultural phenomena) and (2) merely exploring philosophical possibilities for its creation and development. I think he does the later, not the former. The book is more 'theoretical' in the sense of commenting upon existing literature (often leaving the reader without proper introductions) than in the sense of forging new concepts and model their interrelations into a new theory. 
The first chapter on multiculturalist discourse offers a useful and critical overview of some multiculturalist theories and their development as being premised upon a deeply ideological concept of culture, called 'culturalism' by Olteanu, following the critique by Eriksen and Stjernfelt's (2012) of the same phenomenon. This ideological concept implies an idea of completely monocultural and monolingual communities and a quite rigid notion of cultural identity. These elements fuel present-day identity politics of recognition. The real problem with an implicitly culturalist idea about multiculturalist phenomena is the very taking for granted that it is possible clearly to define and delimit each culture (as if it were an organism) among others, and thus the belief that all cultures have distinguishable borders in space or time. According to Olteanu, the opposite is the case: "the main characteristic of culture" (missed by the multiculturalist theories criticized) is that "cultures do not have distinguishable borders in space or time". Thus, a culture does not have "an external borderline that can be touched or crossed and which, consequently, would react (positively, negatively or otherwise) when touched from the outside, as a biological organism would react" (Olteanu 2019: 2).

Here, one could notice that the likely existence of fuzzy borders between cultures, and the real vagueness of various notions of culture, does not imply that distinct cultures do not exist or cannot be individuated (just like the fact that a border between a forest and a meadow is a fuzzy one does not imply that they are not two different ecosystems). I think the main target of Olteanu's critique of the culturalist conception is better described as its essentialism than its insistence upon clear-cut boundaries. If culturalism essentializes the mode of existence of any culture, the challenge is to develop non-essentialist accounts of culture that might retain some features of vernacular "culture speak" (as when people compare two companies with a flat versus a hierarchical "leadership culture"). In fact, I think this is part of Olteanu's project.

Apart from essentialism, another aspect criticized by Oltenau is the totalizing perspective of culturalism, that exaggerates the causal power of enculturation (socialization into a culture), as if a person could only belong to or be influenced by one single culture - why should there be a limit to how many cultures, genres, or styles can affect a person? Indeed, I do not experience my friends to be limited this way. Olteanu argues that this idea comes from a language-centred theory of culture, which regards human cognition and organization as deeply linked to a single specific language. In such a conception, language and culture are like dual aspects of one indivisible whole (the nation, its native people, their way of life) and a person has to belong to only one such holistic entity, or at least he or she is typically "enculturated" into one such culture. Think of yourself, dear reader: To which culture do you really belong? How to single out a specific one? 
The question is not just a descriptive one, or one of social scientific understanding of ourselves as members of multiple groups within a society, it is also political. Olteanu criticizes the tendency within this version of multiculturalism to elevate a group's particular "rights" over universal human rights. Even though one may be sympathetic towards a political stance fighting for a higher degree of self-determination for minority groups, the question about the legal framework for how 'self-determination' is to be enacted should be addressed. There is a problematic tendency for some brands of politically motivated multiculturalism to seek to prioritize supposed special habits, ways of life and local understandings of any minority culture over and above the universal human rights or the common laws within a liberal democratic state governing all its members. As Olteanu (2019: 5) points out, such "clusters of organizations, alternative to the state, are dangerous both for liberal democracy at a state level, as they upset the rule of law, and for their own members. They obstruct the state from defending the rights of individual members of the minority group by the claim that the state does not understand their own cultural norms. [...] in such situations, minority group members who are seen as culturally deviant within their own respective groups are particularly vulnerable and often oppressed by the community to which they supposedly belong." He quotes a question that the Israeli-American professor of law Amos N. Guiora raised in his Tolerating Intolerance: The Price of Protecting Extremism (Oxford University Press 2014), namely "how much can a democratic society tolerate the intolerance of its composing communities? That is to say, when does a society become oppressive and undemocratic on account of its pretense to all-encompassing tolerance?" (Olteanu 2019: 5). Olteanu rightly points out that this version of multiculturalist theory appears to ignore that cultures are intrinsically pluralistic.

In contrast to the aim of defending diversity, multicultural theories too often end up in a kind of separatism, the view that a human being can never fully participate in the socio-cultural life and organization of more than one cultural group. For instance, if an Italian, to use Olteanu's own example, migrated to the USA, she would never fully participate in American culture and society because of her Italian background. The best she could do is to find a community of Italians in the USA where she can blend in. Still, according to Olteanu, there is hardly anything like 'Italian culture' or 'American culture': there is a diversity comprising many cultures within the borders of a modern state. Socio-cultural organization is very different in Milan, Rome and Palermo. The problems that an immigrant from Palermo will face in New York are in many respects the same as she might face in Rome. 
The separatist outcome of current versions of multiculturalism is argued by Olteanu (and his predecessors Eriksen and Stjernfelt) to be grounded in American anthropology, continental structuralism and "the linguistic turn" in philosophy of language. These intellectual currents developed their theories of culture in the aftermath of the Second World War, and shared cultural relativism as a common denominator. Against these relativist theories, Olteanu generates his alternative or at least explores its possibility - based on theoretical resources from recent scholarship, particularly in semiotics and biosemiotics, including new readings of Peirce (but also Husserl and Merleau-Ponty) that develop Peirce's pragmatic semiotics as a realist phenomenology of meaning. This allows one to see that cultures are not independent and separable phenomena. Thus, Olteanu dynamizes the concept of culture, seeing cultures as pluralistic and as having vague borders: Each culture is diffused with other cultures! Not only the meeting of cultures, but any semiosic phenomenon implies plurality and generates diversity. The meeting of two cultures, A and B, does not have to be more semiotically complex than the dynamics within A itself, to the extent such a dynamic can be singled out. The mutual involvement of A and B with each other does not leave them unchanged, in "relativist isolation" or original shape, "because no such shape ever existed" as Olteanu (2019: 19) writes. He also draws upon a convergence between educational theories and (bio)semiotics that opens for a new perspective upon the interconnectedness of life, sign action (or meaning), and learning.

\section{Culture is multi-culture}

Most of the book's chapters take the form of commentaries to theories within the humanities, with the reader hoping that this will lead up to the author proposing his own theory. In the second chapter ("Cultural relativism and the politics of recognition") Olteanu discusses the role that non-Peircean semiotic theories based on notions of opposition and difference (de Saussure, the structuralist, and the poststructuralist traditions) - have had for cultural theory in general and for the concept of cultural identity. He criticizes the inconsistencies of cultural relativism and its dangerous implications for politics, such as separatism and disrespect for universal human rights. Drawing on the recent examples of the Brexit referendum and Catalonia's attempt at a secession from Spain, he concludes that both nationalism and a multiculturalism-endorsing isolationism originates in culturalism: both the political left and right "take advantage of the relativist epistemology that culturalism supposes, namely that there is no universal nonor pre-cultural axiology of values by which an act can be deemed moral or not, 
right or wrong, to impose a political ideology. In this view, any human action is meant to be morally judged within a culture's own relative axiology. This is one of the main reasons revealing the need of developing the present semiotic approach to multiculturalism, free of holistic determinism and cultural relativism" (Olteanu 2019: 52). I am not convinced that culturalism alone can bear the burden of explanation for the resent surge of popularistic nationalisms we can see around the world, and the reader could supplement this with the analysis by Fukuyama (2018), providing additional explanatory factors such as the democratization of the politics of dignity (the demand for recognition by various groups), the expressive individualism in modern societies, and the politics of resentment.

In Chapter 3 ("Semiotics and multiculturalism") Olteanu argues in favour of "a mereological semiotics", comprehensive of the crucial roles of iconicity but also of indexicality. His use of mereology - often understood as a theory of parts and wholes - in its adjectival form to characterize semiotics is never explained in detail, which is typical of Olteanu's writing in ways that are incomprehensible to outsiders (a bit unfortunate for a book about multicultural communication). Those acquainted with Peirce may guess in what sense his semiotics is mereological, but even Peirce scholars will disagree about how exactly the semiotic parts and wholes are interrelated. Apart from this, the chapter advocates for the necessity, for any cultural theory, of what Olteanu calls 'biocentrism'. I think Olteanu is trying to say that any theory of culture should be rooted in a theory of human beings seen as biological phenomena. Strangely, he never explains what precisely biocentrism is, only that it is achieved in biosemiotics. Yet biocentrism can have different meanings in ethics, metaphysics and epistemology, and I think the biocentrism related to biosemiotics is primarily an epistemic one (knowledge acquisition is seen as universal property of all biosystems, not only in humans, as anthropocentric theories would have it). Later on, it becomes clearer that Olteanu is searching for a theory that would root all human capacities for communication and understanding in some bio-cognitive and bio-social capacities, shared across our species' different cultures, and shared with our human ancestors and some non-human animals.

The book's fourth chapter ("Language, culture, and pluralism") takes a closer look upon pragmatism's different versions and their consequences for multiculturalism. Pluralism was already a hotly debated topic in the early pragmatism of Peirce, James, Dewey, and the Polish-born American philosopher Horace Kallen, who in the early 20th century argued against the notion of the 'Americanization' of European immigrants. Some of the pragmatic accounts of pluralism, as Olteanu's nuanced discussion shows, resulted in arguments in favour of isolationism as a means to preserve diversity. He argues that biosemiotics - because it inherited 
Peirce's version of semiotic pragmatism, including Peirce's specific concept of continuity - implies a better construal of diversity and pluralism that does not endorse isolationism. Cultures are not to be seen as separate languages, as this would easily lead to a cultural relativism: Thus, "culture cannot be conceived as isolated: culture is multi-culture" (Olteanu 2019: 81). In this chapter Olteanu (2019: 82) admits that a "fully and explicitly semiotic approach to multiculturalism has not yet been developed" and leaves the reader impressed with his scholarly capacity to clear the undergrowth of a theoretical wilderness, though leaving genuine theory construction behind as an unfinished project. What we are offered is instead a hope that a biosemiotic approach "can offer fresh and critical insights by making possible the bridging of, for instance, cultural and evolutionary anthropology and sociobiology and sociolinguistics" (Olteanu 2019: 82).

\section{Basketball and phenomenal proximity}

The fifth chapter ("Biosemiotic multiculturalism") claims to develop a biosemiotic approach to multiculturalism, as an alternative to existing anthropocentric and language-centred cultural relativist theories. It is said to be founded on Cobley's (2016) biosemiotic approach to culture, and Olteanu (2019: 90) claims that "human-specific modelling systems, hence the cultural organizations of humans and their scientific pursuits, are rooted in non-linguistic modelling systems as stemming from each species' and individual's semiotic competences". Strangely, this should imply that "our cultural organizations cannot make abstraction of the physical (hard) environment and, more importantly so, of the environment as perceived by human physiology" (Olteanu 2019: 90). A charitable interpretation of this convoluted sentence would be that human physiology and the biophysical environment constitute basic preconditions for the existence of human culture and its organizational forms. This, however, is hardly surprising and makes no constraints on the human capacity for abstract thought.

Olteanu may be right in pointing to a continuity in the modelling of natural environments between human and non-human organisms. This view suggests that

[...] all human beings, regardless of linguistic competences and cultural peculiarities, understand reality starting from the same, basic semiotic competences, which come with human body morphology and physiological features. In addition, many such competences are shared across species, implying that modelling systems of distinct species overlap to various extents. (Olteanu 2019: 90) 
Though one can hardly disagree, it would be surprising if that should imply that biological variability of our individual features (height, weight, skin colour, physiognomy, etc.) should be the dominant predictor of our capacity to share phenomenal worlds, as Olteanu seems to think:

Arguably, a person who lives in Barcelona, and is a native speaker of Catalan, and is two-meters high is phenomenally more proximal to a native speaker of Urdu who lives in Lucknow and is two-meters high, rather than to another Catalan native who lives in Barcelona but is one-and-a-half-meters high. The two taller individuals, for instance, could rather play basketball together than with the shorter person from Barcelona. They would share phenomenal worlds (umwelten) to a larger extent, having common experiences, such as of how is it like to be taller than the average and how are they perceived in their societies. (Olteanu 2019: 91)

Olteanu reassures us that he does not want to underestimate the immediate counter that "the two speakers of Catalan can much more easily express to each other their agreements and disagreements, negotiate and, in general, collaborate" (Olteanu 2019: 91), but he does not use this to go back and discuss critically what the idea of sharing phenomenal worlds or umwelten really implies for talking animals like us. This omission and the very quote indicate a limit, rather than an advantage of a purely biological (or even biosemiotic) approach in understanding such a multidimensional notion as the phenomenal worlds of human beings, shared or not. This limit is related to the potential threat of reductionist simplification (well known from previous debates over sociobiology and evolutionary psychology) that conceptualizes all human variability (social, cultural, psychological) as basically biologically determined. Even to some proponents of the umwelt theory as applied to humans, the quoted passage would be problematic, as it fuses distinct levels of bio-cognitive processes that should be distinguished, just like Thure von Uexküll (1986) distinguished between levels of semiosis in vegetative, animal and human sign systems.

To recapitulate, a central reason why a multicultural theory (and any theory of culture) according to Olteanu must presuppose a biological theory is that the human capacity to communicate is rooted in our biology, and thus, a theory of communication must similarly require a biological theory. Is such a theory developed by Olteanu? He is rather laying the foundations upon which the bricks and mortar for such a theory can later be laid (which is of course a legitimate enterprise when so declared). To illustrate the approach to theorizing, consider this quote (where each asterisk substitutes a reference in the original text): 
[...] biosemiotic modelling theory accounts for a mereological theory of culture, wherein cultures are inner pluralistic, and their components have relative independence from the whole. As such, since cultural structures can be inherited from one culture to another, neither can cultures be clearly and strictly be separated one from the other. As Cobley observes, Sebeok's semiotic notion of environment, umwelt, as inherited from von Uexküll is best translated into English as model [*]. In Sebeok's words, "All organisms communicate by use of models (umwelts, or self-worlds, each according to its species-specific sense organs), from the simplest representations of manoeuvres of approach and withdrawal to the most sophisticated cosmic theories of Newton and Einstein" $\left.{ }^{*}\right]$. In this view, the biosemiotic approach to cross-cultural communication largely coincides with ecosemiotics $\left[{ }^{*} ;{ }^{*} ;{ }^{*}\right.$. Biosemiotics is also compatible in most ways with the semiotic framework of education $\left(\right.$ see $\left[{ }^{*} ;{ }^{\star}\right]$ ), termed edusemiotics $\left[{ }^{*} ;{ }^{\star}\right]$. The edusemiotic framework also underpins a construal of learning as coextensive with living, liberated from the narrower scope of pedagogy and educational sciences. This account of learning recommends regarding intercultural communication as a learning phenomenon. (Olteanu 2019: 106)

Apart from loosely (i.e., without much detailed argument) relating some concepts modelling, culture, environment, organism, communication, representation, etc. - to one another and referring to previous theoreticians who juggled with those concepts in various ways, the text proposes some things these theories "do" epistemically (one theory "accounts for" another, one approach "largely coincides" with another, or is "compatible in most ways" with another, one "accounts" for some phenomenon, or "recommends" to regard something as something else, etc.). What is happening in this paragraph, as in most of the chapter, not to say the whole book, is an attempted amalgamation of previous perspectives, fields, "theories", and ideas into a perspective that might be called a theory, but could also, more modestly, be called exactly that, a perspective, a point of view, a complex idea from which a theory may later be developed. This is not an unusual 'style of reasoning' (to use a concept developed by A. C. Crombie and I. Hacking, see Hacking 2002) within the humanities, and it is highlighted here more as a declaration of content than as a critical comment, but for a newcomer or even for a fellow traveller of one of the mentioned approaches, it would still have been nice to have had a more systematic and "slow" treatment of the many theories mentioned. For instance, nowhere in the monograph can one find an explanatory exposition of Sebeok's distinction between primary, secondary and tertiary modelling systems; it is mentioned in passing as if trivial or self-explanatory, but at the same time Sebeok's contribution is given high prominence. This free-style commentary, let me call it associative hermeneutics, is a legitimate style of reasoning if it bewares the risk of slipping into merely being 
free associations in the domain of theory, without critical constraints such as historical context, interpretative specificity and structured argumentation ${ }^{4}$. With no such constraints, one can invent "Peirce's solution" or "answer to multicultural situations" (Olteanu 2019: 107) by quoting the master's musings on the categories of experience from the early twentieth century. It is a very open question what that solution really consists in, just as the headline of this part, "The Symbolic Species debate and its consequences for multiculturalism" suggests an answer about consequences that we do not get. Where was the editor at Springer or the series editor who should have reminded the author about unfulfilled promises? Using quotations from Peirce as an argument demands more context specificity, especially awareness about source texts and their status within Peirce's total work. When Olteanu tries to use Peirce's evolutionary metaphysics, including the idea of evolution by 'creative love' (Peirce's so-called 'agapasm') as a stepping stone to his own "theory" of multiculturalism, he writes "With the doctrine of agapasm Peirce offers, besides a full-blown theory of evolution of meaning, a shortcut to what a theory of multiculturalism, in his view, should be based and focused on" (Olteanu 2019: 109). This sentence seems to suggest that Peirce, who died in 1914, had opinions about a theory of multiculturalism; it would look less hilarious had it been suggested as a speculation about what Peirce counterfactually would have thought about multiculturalism.

Some parts of the text commit a fallacy that is unfortunately well known from the history of ideas, namely that of reducing a structural similarity to sameness: e.g., if one discourse has an aspect of relativism, and another discourse also has relativist features, then both basically commit the same errors (assuming that relativism is wrong) and can be subjected to the same criticism. Look at this example:

Kuhn's theory implies that scientific communities determine scientific research as construed within the linguistic possibilities of their technical language which has to be, in turn, determined within the possibilities and structures of the natural language(s) in which research was carried. The semiotic realist reply to this is that Kuhn's position does not justify the falsifiability of scientific hypotheses and the fallibility of scientific theories but, rather, it renders science infinitely subjective, limited and limiting instead of insightful and revealing. Like in the case of Marrone's concept of text [...], it can be argued that, in Kuhn's conception, a scientific paradigm cannot offer conclusive proof of phenomenal evidence. Such is also the reason that led Lyotard [...] to consider metanarratives unconvincing and

4 The structure of a text can be improved by the use of footnotes making the distinction between the main argument and minor explanatory or referential details clearer. Olteanu's text has no footnotes and presents both types of material in a hierarchically unordered manner. 
that postmodernity is the condition of human societies realizing the unavoidable ideological bias of all knowledge. As such, in this view, as Kuhn considers, any scientific progress can only be perceived as due to chance and consisting in a revolution, the unexplainable and accidental happening of scientific paradigms agreeing on a new understanding. It is obvious that the criticism that Eriksen and Stjernfelt address to cultural relativism is the same that biosemiotics [...] addresses to the glottocentrism of (post)structuralism. The same criticism is applicable to linguistic turn pragmatism, with its notion of cultural pluralism, as seen most evidently in Kallen [...]. (Olteanu 2019: 88)

There are some bold parallels suggested, but they are not based on in-depth critical discussions of the extent to which for instance Kuhn can be called a relativist, or of the nuances that Kuhn confers to the notion of 'the falsifiability of scientific hypotheses', here mentioned in passing as something self-evident, and as if falsifiability was a notion on par with the general notion of fallibility. Kuhn actually tried in his own way to account for the fallibility of science, without denying scientific progress tout court, and Kuhn's instrumentalism concerning the criteria of success for scientific work could just as well be seen as having an affinity to pragmatism, even though Kuhn did not embrace Peirce's theory of truth. Kuhn and Lyotard may both be relativists, but their relativisms are quite different. More depth, details and nuances are needed to avoid the analysis to degenerate to a Manichaean story about an eternal big fight between the good realists and the bad relativists.

\section{Collapsing dichotomies, eluding a theory}

In its title the book promises to give the reader a semiotic perspective upon multiculturalism as multimodal communication. The first five chapters said nothing about multimodality, so it is with some accumulated expectations that one comes to the sixth and last chapter, titled "An embodied approach to multimodal communication". It promises to join together the previous discussions with semiotic theories of multimodal communication, with the purpose of setting the ground for a new theory of intercultural communication. The approach aims to address the phenomenology of embodiment and its consequences for knowledge and communication, particularly as expressed in biosemiotics. Already in the chapter's abstract a strong thesis is suggested, namely that "no communicational instance can be labelled as non-intercultural, just like no particular translation can be monomodal". Does that mean that we should give up these distinctions, monoversus multimodality, and intra- versus intercultural? 
Perhaps so, because such distinctions appear for Olteanu to be Cartesian, dualist, and to be traced back to the linguistic turn in philosophy and ultimately to Ferdinand de Saussure's distinction between langue, language as a system, and parole, actual speech (disregarding de Saussure's methodological argument for making this distinction). According to Olteanu, a "non-dualist, non-essentialist and non-ideological approach to culture should collapse the dichotomy between language and speaking" (Olteanu 2019: 116). He claims that biosemiotics eliminates this distinction by its embodied account of meaning where meaning is always embodied in some form. The later may be the case, but in Sebeok's version of (bio)semiotics, the distinction is far from collapsed; it is retained in Sebeok's distinction between primary and secondary modelling systems. Instead of discussing this, Olteanu makes the surprising claim that writing does not represent speech. Speech and writing are simply both to be seen as embodied "modalities that embody meaning" (Olteanu 2019: 116). Again, a strong, actually very radical, thesis, but hardly true in general.

Olteanu then takes up a suggestion by Stjernfelt to develop "a concept of the body which, in itself, makes evident the basic semiotic competences of an organism, i.e., a body concept which entails semiotics" (Olteanu 2019: 116), and he criticizes cultural studies and most of the established textual semiotic approaches to culture for dissociating a text and its morphology. He proposes to use the term 'typography' to refer to 'the morphology of a text'. He refers his reader to a previous section (2.2.) for an explanation of the term 'morphology', but in that section one searches for it in vain. We only learn that in linguistics, "text is thought of as a weaving of meanings regardless of their material morphology, since the double form-content articulation is arbitrary and any content can fit in any form" (Olteanu 2019: 41). Thus, it is unlikely to be the standard linguistic concept of morphology (as the study of the structure of words and morphemes) that is referred to. Olteanu gives a few further clues (apart from references to other scholars), such as the postulate that "the concept of text is necessarily typographic, in the sense that text is a design, not only a dyadic articulation" (Olteanu 2019: 117). But what is design? He quotes some typographic design scholars studying (a vernacular sense of) design processes of text layout or setup, and makes an excursus to the Bauhaus school of design, but does not answer the question of what the morphology of a text really is.

A further hint, however, is given by Olteanu's mentioning of the long and complicated history of the translation (and interpretation) of ancient Greek texts of philosophy through Arabic, Al-Andalus language and script into Medieval Latin language and script, and up to the present. By claiming that that meaning is embodied, Olteanu thinks that "it appears naive to assume that the designs 
of the manuscripts and the many transductions [sic] undertaken are irrelevant for intellectual history". This may be so, but he does not tell us precisely how "the morphological design" of these texts is relevant and can be seen as impacting upon the specific ideas they express, or how the constraints of translation have something to do with embodiment. The "embodied approach" will hardly mean that the text has a body (except perhaps metaphorically), or that we should take an interest in the body of the translator to understand the translation better? The discussion about double articulation in traditional linguistics and in semiotics, that takes up a large part of the chapter, does not help answering this.

So, what about multimodality? We learn that zoosemiotics, as it is grounded in biosemiotics, "already consists in a theory of multimodal representation, assuming that animals make sense of their environment through the use of all available channels of sensory perception" (Olteanu 2019: 127). At this point, Olteanu integrates Darwin and zoosemiotics (with the series editor Martinelli) in his Manichean narrative about the fight between an evil modernist Cartesian "depreciation of embodied presence and morphology" (Olteanu 2019: 127) and a coming age of embodied multimodal presence. Cartesianism is seen as "linked to modernity's monomodal expressivity. Philosophers in the Cartesian tradition have considered nature and culture as an irreconcilable dichotomy because it was the print medium that framed the mind of modernity" (Olteanu 2019: 127). Against this, Olteanu points to the use of new digital media (integrating still and moving pictures with text) as motivating "an iconic turn" in studies of art, learning, and communication. He expands the extension of the concept of text claiming that "design and urban planning are instances of typography because they constitute texts of which society is weaved. Text as such, biosemiotics reminds us, is morphological" (Olteanu 2019: 128). In my opinion this makes the notion of 'text' quite fluffy, and we would probably have to keep or rename the more traditional text concept when talking about texts in the ordinary sense.

Olteanu makes this move in a section called "Text as multimodal presence" but the forms or modes of existence of this multimodal presence are not analysed, he only states that all communication "starts from bodily presence" (Olteanu 2019: 127). Instead, his stream of commentaries continues in a section on "Ecosemiotics as a digital media theory". Here, the contributions of Marcel Danesi, Gunther Kress, Crispin Thurlow, Kristine Mroczek, Marshall McLuhan, Timo Maran, Kalevi Kull and many others are commented upon. Following the wave of ecocriticism Olteanu suggests that "during the age of modernity ways of production were developed that are harmful for the natural environment because the modern medium of printed text alienated human society from some of the basic characteristics of its possible umwelten. [...] human beings model 
their environment multimodally, by using a variety of sensory channels. Thus, the monomodal medium of the textbook, as spread by print technology, proves un-ecological for human society" (Olteanu 2019: 132). I wonder how Olteanu can forget that a "monomodal" text like a novel, by its specific contents can convey whole universes of sensual sceneries appealing to the reader's many modalities? Just like culture always involve multi-culture, Olteanu should acknowledge that monomodal texts engender multimodal interpretants, and if (remember the strong thesis from the chapter's beginning) "no particular translation can be monomodal", why should this not also apply to interpretation? (Another question, apropos the "un-ecological", is whether today's multimedial devices - TVs, computers, tablets, smartphones, etc. - are less harmful for the environment than printed books and papers; but such "empirical" issues are not touched upon.)

A brief section announcing "A biosemiotic account of typography" follows (still without defining typography, or even discussing it) before the final section of the chapter, "Writing as scaffolding", in which we can read this uroboros of an argument:

The crucial contribution of biosemiotics stands in explaining the relation between the morphology of the body and its behaviour as iconically developed. By this claim, biosemiotics holds that models, or texts, provide phenomenal evidence. While claiming phenomenal evidence, texts, which in this case are ecological relations, continuously undergo re-modelling. Their reshaping is what we came to call writing. Writing, thus, consists in the iconic manipulation of typographic forms. (Olteanu 2019: 135)

Reading such a passage, I am not sure how to make sense of it - on what level of generality and by which concrete examples one could illustrate its points, just to demonstrate some minimal understanding. Clearly, for biologists, there are lots of very crucial non-arbitrary relations between the behaviour of, say, a bat, and its bodily shape, including the internal anatomy of its brain and the neurophysiology of its sensory apparatuses. To which extent such relations can be characterized as iconic (or having also indexical, symbolic or other aspects) is then a complicated task for a biosemiotician to sort out. The role of "models, or texts" (apart from their implied equivalence?) in such an illustration are completely unclear, also regarding any "phenomenal evidence" they might hold. What is the text? And what could it not be? Moreover, we do not know what it is phenomenally like to be a bat, and we even do not know on a general level what our own phenomenal experience of, say, writing by hand or on a computer keyboard or tablet display, is evidence of, if not our thoughts. Furthermore, what to make of the two claims in this passage that texts equal ecological relations, and that their re-modelling 
equals writing? Perhaps it is the ephemeral notion (from the start of this chapter) of the morphology of a text called typography that is fleshed out here as an identity between body and text? Olteanu writes that modelling starts with and is regulated by the body's morphology (which may be true, but how?), and that there is a plastic relation between embodied morphology and behaviour. Again, perhaps so, but it needs to be demonstrated by analysing the specific behaviour and functional anatomy and physiology of human or nonhuman biosystems. There is no attempt in Olteanu's writing to delimit the scope of his wild-growing analogies and associative hermeneutics, or to ascertain the borders of validity for the many suggestions (no 'scoping reproducibility' cf. Leonelli 2018). If "iconic manipulation of typographic forms" was all there were to writing (as normally understood) we could see the sorting out of garbage into paper, plastic, glass, and metal as a special case of writing.

This last section of the book comments upon the notion of semiotic scaffolding, and we learn that "small linguistic units, such as phonemes or letters, are structurally similar to the words and phrases to which they contribute" (Olteanu 2019: 136-137), yet without getting a characterization of the form of this similarity. The chapter ends with these words: "[...], text and model are interchangeable and each of them can serve as the central tool for a media semiotic theory fit for the digitalizing context of global multiculturalism" (Olteanu 2019: 137). Hardly convincing.

So, what happened with the promise to address "multiculturalism as multimodal communication"? The only hint that the long last chapter gives an impatient reader seems to be this: "Digitalization, as a shift from linear and monomodal to multimodal media, reminds that the human umwelt is multimodal. This suggests that communication which involves a plurality of cultures is a sub-case of cross-modal translation. Thus, cross-modal communication is a more appropriate idiom for referring to what has been labelled intercultural communication" (Olteanu 2019: 129). Without letting us know if 'cross-modal' and 'multimodal' communication are synonyms in his vocabulary, Olteanu now subsumes intercultural communication under something called 'cross-modal translation'. What the later term covers is far from clear.

This is not a theory, not even a coherent semiotic perspective. It is disappointing. I guess that the author got caught in the corpus of texts he eagerly comments upon (and does so faithfully, I do not doubt he has a firm grip on the selected material or that the book can be useful for scholars within these fields). To continue the abductive guesses, perhaps there was time pressure in the final part of wrapping up the manuscript for Springer's deadline, in a lonely process of making editorial finish that in "the old days" would have been made in a dialogue with a devoted copy-editor, now often outsourced by the publishing houses. 


\section{Friendship transcending multiculti-culturalism}

Above, in the opening quote, John Dewey describes democracy as a way of living together that cherishes "all the forces that make for friendship, beauty, and knowledge". Olteanu (1990: 12-13) mentions a special friendship between the Sufi Ibrahim ibn Adham and the Orthodox monk Symeon, exemplifying how Christians acquired a deeper grasp of spirituality by learning from Muslims and vice versa. One religious community can achieve a richer understanding of its own spiritual doctrines through dialogue with the other, and in general, dialogue and friendship enhance understanding. Perhaps empirical studies of cross-cultural friendship can teach us something about the discourse on multiculturalism and its limits?

A recent study explored the extent to which people of different origins, natives and migrants, come together in everyday life in Europe, drawing on a data set generated from a survey conducted in 18 neighbourhoods in six European cities: Lisbon, Bilbao, Thessalonica, Rotterdam, Vienna, and Warsaw (Pratsinakis et al. 2017) - the first study on interethnic friendships based on an international data set comparing different neighbourhood types. Despite the fears in public discourses about the supposed negative impact of immigrants and ethnic minorities on social cohesion, the findings indicate that close interethnic relationships are not uncommon in diverse European cities. It also appears that "parallel lives" are not the prevailing norm; in contrast, despite its somewhat apolitical invisibility, "everyday multiculturalism" can work as a cohesive force which resists fragmentation and division.

Another study aimed to understand young people's intercultural relations, their strategies for belonging, and the implications for social cohesion (Harris 2016). It focused on two neighbourhoods of major cities in Australia with populations with many overseas-born residents. Here, government, community organisations and other agencies are very active in implementing initiatives to bring young people of different backgrounds together. The study was critical of such governmental "top-down" multiculturalism (perhaps influenced by culturalist ideology), where social programmes focus on learning about difference and getting along with others: promoting intercultural relations through cultural knowledge exchange and celebration of diversity can fail to address more pressing issues of racism and social inequalities that face young people. Harris' study gave a compelling and thick description of what I was about to call "a cross-cultural friendship" but I should rather say an aspect of friendship that actually exemplifies Olteanu's criticism of culturalism: Harris tried to find out what the friendship between "Ana (18, Polish background, Catholic, born Poland, migrated aged 16, both parents 
professionals) and Marley (17, Samoan background, Seventh Day Adventist, born New Zealand, migrated aged 1, both parents unskilled workers)" (Harris 2016: 511) consisted of. The friends themselves could hardly tell, but in the course of the interview the insight emerged that "it was a friendship that created a space for each to be more than their ascribed identities, and especially to move beyond cultural ascriptions and expectations imposed by those experienced as authorities in their lives, including ethnic communities, families, the school and other social institutions. In this sense, its generative potential was not merely as a 'crosscultural' friendship, but as a space for exceeding these ascriptions" (Harris 2016: 512). Obviously, such friendships have meanings far beyond their capacity to bridge difference and distance and generate intercultural exchange.

As emphasized in another new and very detailed study on friendship in a multicultural setting, friendship is a "key social relationship in the contemporary lexicon of multicultural social relations, given the extent to which friendship is mobilised in lay understandings, as well as more formal integration policy agendas, as an evidential measure of social cohesion" (Vincent, Neal, Iqbal 2018: 23). This book is based on sociological studies of primary schools, seen by the authors as providing a site for mixing across difference, yet they resist the assumption that the processes involved are straightforward. The very word 'multiculturalism' tends to make us focus on cultural and ethnic differences, forgetting other social markers like class, and one of their findings is that both adults and children cross ethnic difference in their friendships more frequently than class difference. This study provides a harmonic blend of original research and theoretical reflections showing how friendship studies may provide a lens to reflect better upon the issues of multiculturalism. Contributions like those of Pratsinakis et al. (2017), Harris (2016), and Vincent Neal and Iqbal (2018) remind us that you can come a long way using common interpretative skills and ordinary human reasonableness, even without expertise in the science of signs and interpretation.

\section{References}

Cobley, Paul 2016. Cultural Implications of Biosemiotics. (Biosemiotics 15.) Dordrecht: Springer. Eriksen, Jens-Martin; Stjernfelt, Frederik 2012. The Democratic Contradictions of Multiculturalism. New York: Telos Press.

Fukuyama, Francis 2018. Identity: Contemporary Identity Politics and the Struggle for Recognition. London: Profile Books.

Harris, Anita 2016. Rethinking youth conviviality: The possibilities of intercultural friendship beyond contact and encounter. Journal of Intercultural Studies, 37(5): 501-516. 


\section{8}

Hacking, Ian 2002[1992]. "Style” for historians and philosophers. In: Hacking, Ian, Historical Ontology. Cambridge: Harvard University Press, 178-199.

Leonelli, Sabina 2018. Rethinking reproducibility as a criterion for research quality. In: Fiorito, Luca; Scheall, Scott; Suprinyak, Carlos Eduardo (eds.), Research in the History of Economic Thought and Methodology: Including a Symposium on Mary Morgan: Curiosity, Imagination, and Surprise. (Research in the History of Economic Thought and Methodology 36B.) Bingley: Emerald Publishing Limited, 129-146.

Olteanu, Alin 2019. Multiculturalism as Multimodal Communication: A Semiotic Perspective. (Numanities - Arts and Humanities in Progress 9.) Cham: Springer.

Pratsinakis, Manolis; Hatziprokopiou, Panos; Labrianidis, Lois; Vogiatzis, Nikos 2017. Living together in multi-ethnic cities: People of migrant background, their interethnic friendships and the neighbourhood. Urban Studies 54(1): 102-118.

Uexküll, Thure von 1986. Medicine and semiotics. Semiotica 61(3/4): 201-217.

Vincent, Carol; Neal, Sarah; Iqbal, Humera 2018. Friendship and Diversity: Class, Ethnicity and Social Relationships in the City. London: Palgrave Macmillan. 